This is an Author's Accepted Manuscript of an article forthcoming for publication in INTERNATIONAL REVIEW FOR THE SOCIOLOGY OF SPORT, copyright SAGE:

https://journals.sagepub.com/home/irs

ISSN: 1012-6902

\title{
The Intersubjective Accomplishment of Power by Medical Professionals within Unregulated Combat Sports
}

\author{
Alex Channon \\ University of Brighton, Hillbrow, Denton Road, Eastbourne, UK; School of Sport and Service \\ Management \\ Christopher R. Matthews \\ Nottingham Trent University, Clifton Campus, College Drive, Nottingham, UK; School of Science \& \\ Technology \\ Mathew Hillier \\ Leeds Beckett University, Cavendish 101 Headingley Campus, Leeds, UK; Carnegie School of Sport \\ Corresponding Author: \\ Dr. Alex Channon, School of Sport and Service Management, University of Brighton, Eastbourne, \\ UK \\ Tel: (+44)1273643746 \\ Email: a.channon@brighton.ac.uk
}




\title{
The Intersubjective Accomplishment of Power by Medical Professionals within Unregulated Combat Sports
}

\author{
Alex Channon, University of Brighton \\ Christopher R. Matthews, Nottingham Trent University \\ Mathew Hillier, Leeds Beckett University
}

\begin{abstract}
The lack of power experienced by medical professionals working in various sport settings has been consistently evidenced by sociologists researching the provision of medical care to athletes. In this paper, which focuses on the work of medical professionals within 'unregulated' combat sports in England, we extend this discussion by focusing on the means by which such professionals attempt to (re)construct power within contexts where it cannot be taken for granted. To explore this issue we conducted 200 hours of observational fieldwork at competitive combat sports events, along with interviews with 25 medical professionals with experience in this field, 7 combat sports referees, and 9 event promoters and their staff. Employing the concept of power as intersubjective accomplishment', we argue that the influence necessary for medical professionals to undertake their work must be actively won within specific situations, principally relying on their ability to tactically interact with various other people. In so doing, we evidence both successes and failures of medical staff in this respect, arguing that such informal means of securing power make caring for the health of combat athletes a particularly challenging proposition.
\end{abstract}

Keywords: Sports Medicine; Combat Sports; Power; Interaction

This paper reports on findings from a study of the work of medical professionals within 'unregulated' combat sports in England. Adopting a micro-sociological focus, it discusses how medical staff employed to work at competitive events in such sports strategically work to secure the influence necessary for the execution of their duties. Before examining related issues within the academic literature, we provide a brief contextual discussion of the organisation of unregulated combat sports in England - including boxing, kickboxing, Brazilian jiu jitsu (BJJ) and mixed martial arts (MMA) providing a rationale for research on this topic.

\section{The Social Field of Unregulated Combat Sports}

The organisation of boxing, kickboxing, BJJ and MMA in England is, at present, a chaotic affair. Although two well-established governing bodies preside over boxing - the British Boxing Board of Control (BBBofC) managing professional matches and England Boxing (EB) overseeing amateur bouts - 'unlicensed' boxing events nevertheless take place outside of the remit of either body (see Wright, 2018). Furthermore, both amateur and professional boxing matches regularly feature on the cards of kickboxing and MMA shows ${ }^{1}$, where boxers meet without the presence of EB or BBBofC officials in matches that do not necessarily adhere to either body's rules or procedures. Thus, while English boxing does have bodies that govern the sport, they do not govern all of it. 
Despite the existence of multiple, self-proclaimed 'governing bodies' for BJJ, MMA and kickboxing, at the time of writing there is no formal governance for these sports in England. That is, competitive events in these sports are run with no accountability to any overarching authority within the structures of national sports frameworks (i.e., overseen by Sport England or UK Sport). Global bodies such as the International Sport Karate Association (ISKA), the International Brazilian Jiu Jitsu Federation (IBJJF) or the International Mixed Martial Arts Federation (IMMAF), along with various English/British affiliates thereof, focus on establishing standardised rules for competition and providing training for coaches and referees. They have little to say about the organisation of events ${ }^{2}$, which are largely operated by private, commercial promotions who can choose whether or not - and to what extent - to affiliate their shows to any one body or another.

In this sense, promoters of shows featuring matches in all four of these sports retain considerable freedom over how they stage events. While this has numerous implications, for our present purposes these include who they hire to deliver medical care, what they expect and demand (or not) of those medical professionals on their shows, and how far they are willing to respect the decisions these medics make. Indeed, while it is a normalised expectation throughout the field that there will be some form of medical cover at any given event, there is no formal authority in place to ensure that this actually happens. ${ }^{3}$

This freedom gives rise to considerable variation in the types of medical personnel and the practices they undertake when working within this field (see Channon et al., 2020). Considering both the widespread popularity of combat sports in England ${ }^{4}$, along with their inherently risky and injurious nature (e.g., Jensen et al., 2017), the question of what manner of medical cover is provided to athletes within these unregulated spaces resonates with public interest in promoting athlete welfare, both generally and within combat sports in particular (for instance, see Moss, 2014; Rice, 2016). Meanwhile, the provision of medical care in various sports has animated much sociological research over the past few decades, providing interesting sites around which to study the peculiarities of sport culture, the nature of professions, the management of risk, and related themes (see Malcolm, 2017) - yet no studies to date have examined this issue within combat sports.

As such, we undertook the present study as a means of broadly investigating this phenomenon. Animating our work were a serious of thematic research questions, one of which we report on in this paper. That is, in the absence of standardised regulatory frameworks defining the scope of their roles and responsibilities in these sports, how do medical professionals ensure that others in the field respect their decisions and comply with their advice?

\section{Power Relations and Medical Work in Sport}

Essentially, this question touches on a key conceptual issue in understanding the performance of medical professionals in sport settings, as with any other context: the importance of power in shaping the everyday practices that constitute their work (Dingwall and Lewis, 1983; Freidson, 1970; Malcolm, 2017; Turner, 1995). In general, the medical profession typically affords its (senior) practitioners considerable power over others, due in large part to the formal institutional authority and professional charisma associated with medicine (Horobin, 1983; Turner, 1995; Rice, 2010). Although the power 
invested in institutions such as the medical profession is always open to contestation, and may shift in form and degree with broader social developments (Malcolm, 2017), so central is the importance of power to medical work that Pilnick and Dingwall argue asymmetrical power relations (favouring doctors over their patients) lie "at the heart of the medical enterprise" (2011:1374).

Despite any generalised power of the medical profession though, the ability of individual medical practitioners to effectively leverage this in practice cannot be taken for granted (Freidson, 1970; Malcolm, 2017). Freidson neatly demonstrates this in his discussion of the situated negotiations between physicians, their colleagues and their patients wherein medical authority is often made "vulnerable to control" (1970:92) by these others. Maintaining control over the conditions of their work and being able to influence their patients' behaviours depends on how well they are able to manage themselves, their colleagues, and those patients or other clients within any given context (Dingwall and Lewis, 1983; Freidson, 1970; Strong and Dingwall, 1979). Such efforts may be more or less affected by the evaluation or interference of their colleagues within the tightly controlled, institutionally-regulated environments of hospitals, or by the beliefs and actions of their patients when undertaken in community-based settings (Freidson, 1960).

Understanding such processes requires attending not only to the agency of the medical practitioner in managing these relationships, but also to that of these others they interact with while undertaking their work. Malcolm (2017:19) summarises Freidson's (1970) thesis on this issue by arguing that "it matters less what physicians 'know' and 'do' than how their subjects evaluate their knowledge and efficacy" in any given situation. The implication of such commentary is that while medicine may enjoy privileged status as a respected, authoritative profession, its work nevertheless takes place in and through negotiated encounters with others, who play at least a partial role in validating the power of its practitioners through acquiescence to their authority.

Following this notion, the manner in which medical professionals secure, defend and exercise power has been shown to be a consistently problematic aspect of medical work within the "unusual clinical environment" of sport (Devitt and McCarthy, 2010:175). More specifically, these relationships are complicated by the conflict in priorities between enhancing and protecting health - which is generally assumed as the role and purpose of medical work - and facilitating athletic performance - typically the central aspiration of most other people in this field (Anderson and Jackson, 2012; Roderick et al., 2000; Safai, 2003). Because the typical, clinical default for dealing with sports-related ill health is to prescribe rest, medics adopting this position risk being ostracised from the social milieu of sport when doing so. Athletes are prone to ignoring their guidance (Waddington, 2012), hiding injuries or deceiving medics about their extent (Walk, 1997), or avoiding medics whose advice they don't like while 'shopping around' for treatment plans which better facilitate their sporting goals (Pike, 2005).

Further to this, sports medics may find themselves in situations where their power is undermined by colleagues within sport, such as coaches, athletic trainers or paraprofessional medical staff, whose perspectives on what is 'best' for athletes more closely align with performance agendas. In some cases, these relationships may involve conflicts which marginalise certain care providers (Roderick et al., 2000). While many physicians may establish effective working relationships with these other staff (Fletcher et al., 2017; Theberge, 2008), such relationships are very likely to be shaped by the trust given to those staff by athletes on the basis of exhibiting a performance-enhancing orientation 
(Malcolm, 2006), and/or other factors such as personal familiarity facilitated by longer-term or fulltime employment in sport (Scott and Malcolm, 2015; Walk, 1997). This indicates that the validity of medical expertise - the "unusual degree of skill or knowledge" (Freidson, 1970:137) that is often taken as one of the bedrock principles of any professional's charismatic authority - is considered relatively unimportant within athletes' relationships with medical staff.

With respect to the environments of medical work, Waddington (2012:219) argues that sport settings represent an amplified type of what Freidson (1960) describes as community-based medicine, wherein doctors, in particular, play "bit part" roles as "service workers" within sports teams. In his study of English rugby club doctors, Malcolm argues that when medical interactions take place at club grounds, within settings where doctors are socially isolated, players enjoy a strong "bargaining position" when negotiating treatment plans (2006:384). Without access to specialist facilities, equipment or the social support of other medical colleagues, physicians are less able to perform certain checks or treatments, insist on conditions such as confidentiality (Anderson and Jackson, 2012), or generally exert the authority that is facilitated by the institutional environments within which many of them are typically used to working. Moreover, for those staff whose work primarily takes place in sport settings - such as sports physiotherapists - the institutional norms and values of sport stressing performance and its enhancement may even come to subsume or replace a sole focus on athletes' health (Safai, 2003; Scott and Malcolm, 2015; Waddington et al., 2019).

Lastly then, the cultural prioritisation of competitive success may see medical professionals experience significant role conflict, through the confusion of being 'part of the team' working to facilitate performance instead of a neutral advocate for athletes' health (Anderson and Jackson, 2012; Waddington, 2012). For some medical staff, such as those working in British Olympic sports, this may involve internalising a prioritisation of the competitive interests of athletes, as "one of the principle considerations" of their approaches to treatment (Scott, 2012:229). For others, this shift towards performance goals may be an effect of coercive or manipulative behaviour by certain figures in the field. As demonstrated in Waddington and Roderick's (2002) study of doctors and physiotherapists in English football, when medical professionals' employment is determined by coaches or managers, whose overarching aim is to improve competitive performance, it becomes "difficult for them to resist threats to their clinical autonomy and/or maintain ethical standards" (Malcolm et al., 2017:1053). Within highly commercialised sports, additional pressures from team owners, corporate sponsors or sports broadcasters may further impinge upon medical autonomy in this way (Anderson and Jackson, 2012; Hanson, 2018). In some circumstances, this foreclosure of autonomy, or its accommodation within a performance-oriented agenda, not only means that athletes miss out on unbiased medical advice; it also invites ethical abuses which place their welfare at risk (Roderick et al., 2000).

While the literature cited above do not represent an exhaustive account of all studies in this area and nor do the phenomena briefly discussed apply uniformly to all instances of medical work in sport - they nevertheless highlight the well-documented potential for medical authority to be challenged, and medical professionals either marginalised or compromised, across various sport settings (Malcolm, 2017; Waddington, 2012). This begs the question: if the ability of medical professionals to exert power within interactions with patients is indeed at "the heart of the medical enterprise" (Pilnick and Dingwall, 2011:1374), how then do medics working in such environments manage to re-establish the power needed to facilitate their work among people who may be resistant to their aims? While a 
good deal of research has effectively charted the lack of power experienced by medical staff in sport, relatively few studies have directly examined how they manage to recuperate this in practice, which we now turn to as the focus of discussion.

\section{Power as Intersubjective Accomplishment}

In addressing the conceptual aspects of this problem, we adopt an interactionist theorisation of power. Specifically, we draw on the work of Robert Prus, who argues that power should not be studied "as an objective condition or a subjective experience, but as a matter of intersubjective accomplishment" (1999:5). Prus defines the term 'power' as implying "an intent and capacity on the part of a person or group to influence, control, dominate, persuade, manipulate, or otherwise affect the behaviours, experiences, or situations of some target" (1999:10). For Prus, such intentions and capacities may be more-or-less facilitated by (macro-sociological) structural factors beyond the immediate context of their execution, but cannot be solely reduced to those phenomena at the point of analysis. Instead, analytic attention is turned towards the (micro-sociological) 'here and now' of social life as it is lived out in practice. As such, this approach to theorising power relations is primarily "attentive to the symbolically enacted realities... in which people conduct their affairs" (Prus, 1999:201).

Central to this perspective is the observation that social life unfolds in diverse contextual environments, with implications for the manner in which different settings for human interaction may enable or constrain the accomplishment of power by people operating within or across them. As Prus writes, "any society is made up of a plurality of human life-worlds and considerations of the power phenomenon... should be approached in manners that centrally acknowledge these multiple lifeworlds" (1999:7). In essence, people who enjoy considerable power over others in one situation may find it difficult to exert influence in the same ways elsewhere; accounting for such diversity requires analytical sensitivity to power as something that is actively accomplished in situ, rather than possessed, stored up and used at will. In the context of the present study, such a proposition is an attractive means of analysing how members of a profession generally considered to hold significant social status, who typically enjoy control over their own work and influence over the conduct of others, may find themselves unable to exercise that power to a greater or lesser extent in particular situations (Malcolm, 2006; Waddington, 2012).

When considering how power is thus won or lost, Prus proposes that human actors be viewed as 'tacticians' engaged in efforts to influence, control, or dominate others (etc.), as well as being the 'targets' of each other's tactics for doing so. While this terminology may imply an active/passive dichotomy, Prus repeatedly emphasises that "the success of people's attempts to shape the behaviours of others generally depends on the target's willingness to cooperate with the agent or tactician in the situation at hand" (1999:145). That is to say that tactical plays at accomplishing power are always at least partially reliant on their target's compliance with the tactician's efforts, requiring intersubjective consensus over the propriety or necessity (etc.) of the tactician's goals for the target in order to succeed in influencing them. Likewise, noting that any given person might simultaneously be both tactician and target, Prus argues: 
Even when people clearly define themselves as targets of influence, it should be recognized that these (same) targets also may assume roles as tacticians in their own right. This means that agents of influence may become (or often are) targets of influence for the very people whose lives they intend to shape. (1999:155, original emphasis)

This presupposes a multi-directional model of power relations, wherein any given tactical exchange is open to contestation, refusal, or even reversal on the part of its intended target(s). And, considering situations wherein multiple tacticians may target each other simultaneously and/or compete for influence over the same target, the social accomplishment of power becomes ever more complex (Prus, 1999). As discussed above, such complexity has consistently been evidenced regarding medical work in sport settings, wherein medics' power might be complied with or directly challenged by their athlete-patients; facilitated or undermined by colleagues; skewed or outright corrupted by others' agendas; and either reinforced or turned towards different ends by third parties (Anderson and Jackson, 2012; Malcolm, 2017; Walk, 1997). As such, its focus on the lived-out accomplishment of power, its sensitivity to contextual specificity, and its attention to complex webs of human agency makes Prus' (1999) theory of power as intersubjective accomplishment a neat analytical tool for research in this field. Before applying this framework though, we account for the methodology used to examine these processes among medical staff working in unregulated combat sports.

\section{Methodology}

Drawing on interactionist concepts necessitates adopting an associated set of methodological tools, which resonate with the naturalistic and pragmatic orientation this theory holds towards studying social phenomena (Athens, 2010; Prus, 1999). As such, we adopted a qualitative design, combining observations with interviews to provide a rounded picture of the work of medical professionals within combat sports contexts. Besides one exception (Kotarba, 2001), no other studies of medical work in sport have attempted to use observational methods, affording us the ability to generate insights into the micro-sociological, lived-out workings of power relations that are rarely captured by sociological researchers in this field.

Our observations were conducted via shadowing medical staff at combat sports competitions across England. Members of the research team moved alongside these staff throughout events, watching how they worked and interacted with athletes and other staff. Observations and field interview data were recorded via field notes, which were later transcribed. In addition, formal interviews were conducted, using semi-structured schedules built out of engagement with prior literature and insights generated through initial exposure to the field. Interviews varied between 25 and 100 minutes in length and were digitally recorded for verbatim transcription. They were mostly carried out either backstage immediately before events, or via video calls at other times.

\section{Sample}

In total, we spent 200 hours conducting observational research. The events visited for observation included 13 MMA shows, 5 mixed-discipline events that mostly featured MMA matches, 5 shows that featured only or mostly boxing, and 2 each of kickboxing and BJJ events 5 . The first author conducted 19 of the observations alone and 4 alongside the other two authors; the second and third authors 
each conducted 2 observations alone. We accessed these sites through a combination of directly contacting promoters to ask if we could visit them, or being invited by medics or other staff to shadow them. With the exception of three internationally-televised, professional MMA shows, the majority of these events were classified within the field as being at the 'regional' level - that is, of a relatively lower competitive standard and usually run on tight budgets (see Channon et al., in press). Nevertheless, each of these shows featured intense, full-contact fighting, replete with the risk of knockouts, concussions, bone dislocations and fractures, lacerations, and a range of kinetic and other types of injury.

Our interview sample was comprised of 25 medical professionals with experience of working at fight shows, as well as 7 referees and 9 event promoters and their staff. $90 \%$ of the total interviewing was undertaken by the first author, with the remainder shared evenly by the other two authors. Interviewees were recruited through a combination of chain-referral sampling, starting with contacts made through active fighters and coaches we already knew, as well as serendipitous contact in the field. The medical practitioners were drawn from a range of different professions and had various specialisms, including orthopaedic surgeons, general practitioners (GPs), accident and emergency (A\&E) nurses, paramedics, emergency medical technicians (EMTs), first aiders, and unqualified trainees. The referees and promotion staff we interviewed typically also had experience in other aspects of combat sports, such as coaching, commissioning ${ }^{6}$, or competing (as did some medics).

\section{Ethical Issues}

Ethical clearance for this study was granted by the lead author's institutional review board, and the principles of the British Sociological Association were adhered to throughout the research. Despite gaining informed consent to shadow medical professionals during the course of various shows, the researchers were careful not to be present during backstage emergency treatments so as not to hinder medics' work in any way. In addition, we only observed medics' direct interactions with athletes in situations where confidentiality was not otherwise being protected (which it almost always was not, as is often the case in sport - see Malcolm, 2016).

\section{Analysis}

Our data were analysed using an iterative thematic analysis (TA) procedure built around both deductive and inductive approaches to coding. In practice, this involved the use of Braun and Clarke's widely-used 'active' model of TA, whereby we reflexively interpreted our data with a mind to a) preserve the integrity of their contextually-situated meanings, while b) seeking out overarching patterns for explaining what was being said and done within the field (Braun et al., 2016). As we clustered our data around potentially useful first- and second-order categories for creating such abstract explanations, we worked backwards to ensure that what we were constructing remained consistent with the data that we believed constituted them. When necessary, we reworked these categories, before eventually ordering them into overarching themes pertinent to the various research questions we were pursuing. The research team met regularly during the coding process to discuss, refine, and ultimately agree the interpretive framework that we were building out of and around the findings. In what follows, we organise our discussion of these findings as they pertain to the topic of medics' intersubjective accomplishment of power within three thematic categories Staging and Props; Soft Skills; and Social Support - before returning to Prus' (1999) conceptual framework to analyse their significance. 


\section{Staging and Props: Projecting and Performing Power}

Firstly, some medical teams attempted to claim authority and defend autonomy by working to control the environments they operated in, structuring the physical and social settings of fight shows in ways which carved out their own, clearly demarcated territory within which to meet, consult with, and treat athletes. An example of what Prus terms an 'enhancing activity', this meant adjusting the environment to maximise their ability to work efficiently, whilst also shaping "images of reality" (1999:174) athletes encountered when meeting them. In the following, a team comprised of two EMTs undertake such work during pre-fight screening:

Steve, who has donned his 'ambulance' jacket, sits behind a desk which dominates the far side of the medics' room, towards which the fighters must walk after entering, and is stacked with expensive-looking medical equipment and a neat pile of forms. Fighters who had been pacing back and forth, bouncing on their toes, or chatting animatedly outside grow quiet and focused when they enter and sit where Steve asks them to, facing him. Rick sits very close, on a stool at the side of their chair, allowing his performance of physical checks to closely invade their personal space while Steve interviews them. Rick does so not rudely, but confidently - he tells fighters what he is about to do rather than ask them, and his manner coveys that he has the right to do this; that this is proper and correct. (Field notes, mixed discipline show)

Such staging of the room, as well as the medics' performances, normalise the expectation that they are competent professionals who sit in a position of power within the social milieu of the fight night, and into whose space - and care - the fighters have entered. This creates a presupposition of medical authority by way of marking out a particular territory that they own and define within an otherwise non-clinical environment.

In addition to physical staging, another common strategy for establishing authority was to 'dress the part' (see Rice, 2010). For Prus (1999), such 'leveraging tactics' are an important means of establishing consensus, by asserting symbols with shared social meanings which have specific implications favouring the tacticians using them. In this sense, most of our sample wore branded polo shirts or green fatigues with words such as 'PARAMEDIC' boldly emblazoned on the back, or other symbolic markers of their role such as smart-casual suits with ID lanyards and blue latex gloves (a common choice among doctors). This presentation of self (Goffman, 1959) signified not just role clarity, but also professionalism, inviting others' trust and respect for the part they played:

It's about professionalism, professionalism underpins the trust the public has in doctors. That's why you come in with the shirt, the formal outfit. You don't come in with shorts or a bathing suit, because you're the doctor. (Elias, ENT surgeon)

Further to this, some others designed their medical firm's logos and company names, which were prominently placed on their uniforms, in ways which emphasised affinity with or direct connection to combat sports, using words and images commonly associated with combat sports subculture. As well as illustrating their medical role, this constructed a sense of shared communal identity between those medics and their athlete-patients, which they could literally wear on their sleeves. Similar to Kotarba's 
(2001) discussion of the social utility of the 'cowboy' aesthetic adopted by rodeo paramedics, this enabled them to move some way towards overcoming the general 'outsider' status of medics within sport settings, noted above (Waddington, 2012).

However, these mechanisms could not always be used, or used to good effect. Medical rooms at the majority of events were staged in ways that were unfit for purpose, symbolically undermining the medics' presence as well as their ability to perform their duties. At most shows, these rooms were shared with fighters' coaching or hand-wrapping teams, event photographers, and other staff; at three events, pre-fight checks were performed in public corridors. This diminished the visible, situational importance of the medical team and their work, whilst simultaneously depriving athletes of confidentiality in pre-fight consultations (see Malcolm, 2016). Such inadequacies were most often blamed on unavoidable issues to do with funding and venue limitations, although we regularly noted that other rooms around such venues might have been repurposed for medical space had the promoters in charge of them been willing to do so. Such poor staging reinforced a point made by several interviewees that, at some shows and to certain event promoters, medical cover was little more than an afterthought in the pursuit of profit (see Channon et al., in press).

In addition to the frequency of inadequately staged work spaces, the use of dress to constitute status posed an even more worrying problem: the usefulness of wearing branded, 'medical' outfits to gain legitimacy in the field gave free license to unqualified providers wishing to masquerade as medics. This was enabled by the fact that "nobody (organising an event) ever checks your qualifications, ever" (Penny, A\&E nurse), while "everybody dressed in green, to members of the public, are paramedics" (Ravi, paramedic). Indeed, as noted elsewhere (Channon et al., 2020), we managed to shadow a team of unqualified 'medics', disparagingly referred to by others in our sample as 'cowboys'. Despite having reputedly forged their medical qualifications, this team managed to secure work consistently, with their leader, Arnold, proudly telling us in an interview that "I put this (uniform) on, and I feel like the part... (People) recognise that we are medics, I think it inspires confidence, their confidence in us". Meanwhile, George, a promoter, told us about a boxing event he'd worked at:

The doctor never turned up, and (the show promoter) couldn't find cover in time so he just got his mate to sit there in a suit with a stethoscope round his neck, tells him not to say anything, "yep, it'll be fine mate, it'll be fine". And this bloke is Chinese right, and so the promoter's going, "oh yeah he's a good friend of mine, a doctor over from Hong Kong and he doesn't speak much English but he's a fantastic doctor".

Yet, despite this possibility of exploitation, as well as the inconsistent availability of tactics pertaining to physical venues, these strategies were commonly used by medics across our sample to define the content and tone of (some of) their interactions with others, meeting with variable success. Next, we turn to how those interactions were undertaken in practice.

\section{Soft Skills: Empathy, Rapport and Assertiveness}

In the majority of their interactions with patients in community healthcare settings, medics are sought out in the first instance by those patients, who are desirous of the services medical professionals can provide to enhance their health (Freidson, 1960; Waddington 2012). However, in the context of our 
study, the most common interaction between medics and combat athletes - pre-fight screening procedures - are not voluntarily sought out by athletes ${ }^{7}$, and have implications that threaten athletes' immediate sporting goals. That is, such screening could result in them not being allowed to fight - an unlikely but much-feared prospect ${ }^{8}$. As reported by the majority of our interviewees, this led to a tendency for fighters to mistrust and thereby act evasively or deceptively towards medics:

(Athletes) will never tell you that they are injured, that they are hurt... They won't tell you anything at the pre-fight medical (because) they think telling you will stop them from fighting. (Dave, aesthetic doctor)

When we were able to observe screening taking place, we often noticed nervous athletes hurriedly rushing through the interviews medics performed with them, answering 'no' to questions that had barely been asked, or filling out surveys without properly reading them. At times, we even saw coaches, and other members of athletes' entourage such as their parents, answering questions for them in a similar vein (see Channon et al., 2020). Many of the medics we spoke to believed that the integrity of these crucial interactions with athletes was premised upon "medical authority and patient deference" (Pilnick and Dingwall, 2011:1374), which was thus threatened. In the face of athletes' and others' mistrust, they adopted two distinct, tactical stances to overcome their targets' resistance and restore this integrity.

Principally, they demonstrated (and often emphasised in interviews) the importance of being empathetic with fighters who were anxious, or using humour to help them relax or build rapport. Perhaps the most consistent illustration of this approach was the tendency for medics to frequently remind athletes, as well as their coaches, that they didn't actually want to stop them fighting, whilst persuading them that they were on the fighter's side either through gentle encouragement, icebreaking jokes, or a demonstration of interest in combat sports:

While they ask questions and take observations, the medics joke and tease the fighters; Ravi asks several if this is their first fight - "Oh, this'll all feel quite strange to you then! Just relax, it won't hurt a bit! Think calm thoughts, you'll be fine." They adopt soft tones, smile almost constantly, and use words such as "excellent" when recording observations. Clive tells one, "that's perfect that blood pressure, right on. Fantastic. Smashing!" At one point, a fighter jokes that the next time she signs a piece of paper, "it'll be to get into the UFC!" Ravi laughs and tells her "get me along to be the paramedic, I'll do it for free so I can watch the fights!" (Field notes, MMA show)

Such work helped the medics overcome the confrontational manner in which some fighters (and their coaches) approached medical supervision, bridging the gap between ostensibly opposing camps: one concerned with sport, the other with health. Thus, empathetic overtures were not only used to charm athletes into deferential stances but also illustrate "affinities of interest" (Prus, 1999:180) through overtly positive attitudes towards combat sports. Symbolic demonstrations of this affinity worked to dismantle suspicion of medics' intentions towards sabotaging athletes' competitive chances, replacing this with images of the medic as a supportive member of the combat sports community. 
The second tactic employed here involved the use of a more direct and assertive approach to these types of interactions. As alluded to above regarding Rick's confidently intrusive performance of physical checks, medics would boldly perform authoritative actions, embodying confidence and assuming the right to dictate to uncooperative others. This demeanour was summarised neatly in an interview with A\&E nurse Victoria and her paramedic colleague, Rose:

Victoria: I've changed my style, I'm not a nurse when I do this, I'm a medic. I've been taught to step back, you don't go (in a quiet voice) "ah, are you ok? Let me just..." no. Here you're like, (in a loud voice) "Right! Come 'ere you! Be quiet, and now tell me..."

Rose: $\quad$ Yeah there's no room for nursing here!

Victoria: " "...sit down, shut up, and let me look at your eye. No, no, no! Let me look at your eye!" In A\&E if I did that I'd have a complaint, "oh that nurse was so rude to me." But in this world you speak as you find.

Rose: $\quad$ You gotta be up there and in their face and have that authority about you.

In observations and interviews, both Ravi and Clive, and Victoria and Rose, each demonstrated both of these strategies at different times. Balancing these two approaches by deciding whether to charm or chastise others was highlighted as a key 'soft skill' by interviewees. The ability to relate well with athletes and adjust their style of interaction to win cooperation was something medics told us they'd learned during their day jobs within the National Health Service: "In our day-to-day job that we do every single day it's the same, building a relationship with someone instantly, it's a job we've done for so long" (Arthur, advanced paramedic). These two strategies - and the ability to effectively choose between them - neatly illustrate the need for reflexive, situationally-attuned tactics in order to socially accomplish power within and through interaction with one's targets of influence (Prus, 1999).

However, not everyone we observed in action had the ability or apparent inclination to use such approaches, while several interviewees told us stories of others who had failed to adapt well to the demeanour needed in combat sports settings, making for poor colleagues as a consequence. Moreover, even medics who generally established camaraderie with athletes were not always able to maintain effective relationships with them; they too could be dismissed and ignored on a whim. For instance, Steve fell afoul of an uncooperative coaching team, with whom he otherwise had good rapport, when trying to administer post-fight care to an emotional athlete:

As Steve reaches the losing fighter, who had submitted to a knee-bar hold, the young man turns away, hurling his gumshield to the floor. He is very angry; he refuses to look at or talk with the medic. After a few seconds, the referees allow the coaches into the cage, and they push past Steve to reach the injured man. Steve exclaims, "You need to let me do my job, I'm here to help him, I need to do my job", but the coaches - who had earlier been genial and shared jokes with Steve at the medical desk - tell him to "piss off". Rick tells me, "We need to see him, yeah, he's hyperextended his knee so he might be hurt". At a break after the next fight, Steve goes backstage but returns shortly after, shaking his head; the coaches refused to let him near. "They just bullied me off. He's outside crying still." He would try again later on, only to find the fighter and his team had already left the venue. (Field notes, MMA show) 
As with the first set of tactics then, those listed here remained variably successful. As such, medics' ability to control the physical settings for interaction, deploy symbolic markers of authority or community belonging, and charm or dominate athletes, all constitute tenuous methods of accomplishing power. In the next section we discuss how wider social support could shore up these other strategies.

\section{Social Support: Reputations and Relationships}

A third category of tactics used to accomplish power related to the various ways in which relationships with others could be leveraged in medics' favour. Of primary importance here were personal reputations in the field, coupled with the development of trust and respect through a consistent presence at fight shows. These were often held up as being vital for constituting medics' status:

I think we all have very good reputations and when you do the shows a lot you get to know (the fighters). A lot of them have my phone number and they'll phone through if they need advice on things. (Penny)

The more you do this... the more you know them. And for the people who know you, it's highly unlikely for them to disrespect your decisions. They might be disappointed but they will respect your decisions. (Elias)

For some medics, the development of trust and reputation, shared by word-of-mouth around the combat sports community, was seen as important in winning them more work. This extra work then meant they could come into contact with athletes more often, ultimately leading to stronger bonds of trust with individuals as well as growing acceptance as an 'insider' in the field of combat sports. This neatly mirrors the findings of numerous studies in the wider literature regarding the value of medical staff's long-term contact and comprehensive types of work with athletes for facilitating open and mutually-trusting relationships (Kotarba, 2001; Scott and Malcolm, 2015; Walk, 1997). In previous studies where medical staff are embedded in sports teams - particularly if employed there full-time this trust has every opportunity to develop over time. In our work though, medics' contact with athletes is more transitory, revealing an additional dynamic: the construction of a 'virtuous cycle' between presence at events, a good reputation, and increased respect.

With regard to more immediate forms of social support, and in contrast to the obstructive role third parties could sometimes play, soliciting the aid of significant others when dealing with uncooperative athletes represented another tactic often used. Perhaps the most significant example of such direct support in the combat sports milieu came from referees. Typically, these officials had extensive experience of competing themselves, as well as coaching or otherwise working in combat sports, sometimes at the highest levels of competition; some could even be considered celebrities on the basis of this experience, giving them a fair degree of situationally-specific charisma - or "mystique" (Prus, 1999:179). Whereas medics' roles were often poorly defined, with the ever-present risk of being seen as outsiders in the field, referees' universally-understood role and central, highly visible insider status earned them a significant amount of respect from fighters, making them potentially strong mediators of authority in the combat sports milieu. 
Several medics told us of the importance of securing referees' support. For Elias, doing so was "very important; it's like the same relation that a doctor needs to have with the nurses". In this regard they drew on very similar tactics as to their efforts to demonstrate community affinity and establish relationships with athletes. For some, such as A\&E consultant Luke, "top referees know us, we've worked with them plenty over the last few years so we've got a good rapport with them, you know you can trust them, you know how you can communicate with them". Indeed, for many medics we observed, referees were often explicitly on their side. This was made clear to fighters during 'rules talks' before fight shows ${ }^{9}$, where the admonition to respect the judgement of medics was frequently made. Referees also regularly demonstrated deference to and respect for medics' opinions, soliciting their help and - for the most part - accepting their judgement on decisions to stop fights, which were rarely popular with fighters or spectators. Here, referee Hugh (supported by his colleague Jon) defers to orthopaedic surgeon Davi's advice following an illegal strike to the back of the head:

Hugh immediately calls Davi into the cage. After a brief examination, Davi shakes his head and converses with Hugh, who then waves his hands above his head to signal the end of the fight. I ask Hugh later about the decision to call in the doctor. He tells me, "They were concussive blows, so yeah, no question, to be fair to the fighter I had to call him in". Jon adds, "Yeah, why mess around? Just get the doctor straight in, do pretty much whatever he says." (Field notes, MMA show)

However, as with the other two strategies discussed, medics' reliance on others' support, as well as the value of a strong reputation, were also imperfect means of securing authority. Despite assurances given to us by medics, referees and promoters during formal interviews that medical judgement over fight stoppages was sacrosanct, we saw four occasions during our fieldwork where this was directly undercut or overruled in practice, with no support forthcoming from these other players. The clearest example of this also further illustrates the vulnerability of reputation and insider status as a means of accomplishing power. Here, a team consisting of Penny - described by many in our sample as having "so much respect in this environment" (Rose) that several promoters would "only use her" (George) for their shows - and Rose - an experienced combat sports medic and a boxer herself - attempt to stop a fight due to a deep, heavily bleeding cut above a fighter's eye:

An elbow connects cleanly with Jim's face; seconds later, blood spurts out in grotesque, rhythmic pulses from the side of his head. The referee quickly calls the medics to attend. Directly in front of me, Jim begs Penny, "Please, please don't stop it. Please, I wanna fight!" Penny and Rose both tell him to keep still while they apply pressure. The promoter, a close relation of Jim's and also his coach, has stepped up alongside Rose on the ring apron. It is clear there is a disagreement between them. A short period of time passes before they step away, and the cut is still bleeding. Rose's face is a picture of fury; Penny holds a blank look. The judge to my left shrugs when I glance at him; both fighters step back to the centre of the ring and the action restarts, while blood continues to run freely. Rose leans over and tells me, "The fucking promoter won't listen. Won't let us stop it." She shakes her head and purses her lips, adding, "This should not be allowed. Fucking promoter overruled us! He's in his corner for fuck's sake!" The fight - as well as the bleed - continued for a full five rounds. (Field notes, kickboxing show) 
Despite what many of our interviewees described as the self-evident importance of medical work in the combat sports environment then, medics could not only always rely on others' trust and respect to support or facilitate their work within it. As with staging and interactional strategies, these tactics also remained imperfect means of securing power. Next, we return to the conceptual framework outlined above to draw some general analytical conclusions from our study.

\section{Discussion}

In making sense of these findings, we emphasise three principle conceptual points regarding power as an intersubjective accomplishment (Prus, 1999), and the uniquely challenging environment of medical work in sport. First among these is that power is something which must be actively constructed through situated action in specific scenarios (Prus, 1999). The corollary of this observation is, of course, that power cannot be taken for granted and must therefore be viewed both in processual terms as an ongoing project, but also in dynamic terms as something which may succeed in one context or moment, only to fail in the next.

Examples of this abound in the data discussed above, but it is particularly well-illustrated in the attempts to shape and control space for medical interactions. This tactic went some way towards managing the previously demonstrated undermining effects of working in sporting rather than institutional medical spaces (Malcolm, 2006), yet the impact it had on medics' work was clearly limited by the availability of venues amenable to this strategy, while also being confined to the moments within which interactions actually took place in those reconstructed spaces. Compare, for instance, Steve and Rick's successful management of their pre-fight screening with the failure of Steve's authority to administer post-fight care detailed later on. The uncertainty of power in this environment therefore necessitates continual effort, balancing a mix of tactics as situational parameters shift and change.

The second observation to note is that the accomplishment of power is an inherently social phenomenon, one which "generally depends on the target's willingness to cooperate with the agent or tactician in the situation at hand" (Prus, 1999:145). In our study, as throughout much of the literature on this topic (e.g. Pike, 2005; Waddington, 2012), athletes' resistance to medical interventions that might prevent them from competing were consistently evidenced. While medics developed numerous strategies for overcoming such recalcitrance, and many felt confident in their ability to effectively deploy these in practice, they also had to reckon with interference from others in the field. Considering the role of third parties in mediating the success of their various means of impression work, the capacity of coaches and peers to reinforce or enable athletes' uncooperative stance towards medics illustrates Prus' (1999) discussion of the obstructive roles such others can play within tactician-target relationships. Here as elsewhere, the charismatic status, "privileged relationships" (Prus, 1999:196), or economic advantages enjoyed by other individuals in this field clearly left medics facing an uphill struggle for constructing and maintaining whatever influence they were able to carve out (see also Anderson and Jackson, 2012; Roderick et al., 2000).

That being considered though, significant others in the field were also able to be mobilised as useful allies by medics at other times. Following the observation that "those accorded mystique by particular targets may more readily be able to influence those targets" (Prus, 1999:179), medics were often 
aware that they could make strategic, second-hand use of such players' situational charisma. As such, they needed to tactically engage with referees, along with promoters, coaches and others, as secondary targets in the quest to accomplish power within their dealings with athletes. When this was managed successfully, the harmonious coordination between referees and medics was reminiscent of the smooth operation of 'multi-disciplinary' medical teams noted in several other studies (Fletcher et al., 2017).

Lastly though, the third point we wish to emphasise is that when medics were able to establish power through these various means, the grounds upon which this power rested had very little to do with their medical expertise. A consistent finding throughout much of the literature we have discussed above, this comes about as a consequence of the conflicting priorities between sport performance and healthcare that often arise in such contexts, which reduce the situational importance of traditional mechanisms of medical authority per se. Our data provide a number of illustrations of the observation that medical professionals' unique expertise - which underpins not only effective practice but also the ethical legitimacy of exercising professional power over others (Freidson 1970) - matter less in practice than does the ability to successfully manage interactions in context (Malcolm, 2017).

This phenomenon has numerous implications. Perhaps foremost among these is the fact that, while previous research shows underqualified or lower-ranking staff thereby wielding greater influence than (or even holding power over) more highly-qualified doctors (Malcolm, 2006), here we have shown that it also creates space for outright fraud in the provision of medical care to athletes. As Prus summarises, the "same capacity for achieving shared meaning(fullness) with the other means, rather simultaneously, that people are open to messages that may be intentionally (as well as inadvertently) deceptive" (1999:175). Insomuch as medics' qualifications are 'never checked' by promoters hiring them, the symbolic purpose of those qualifications in communicating legitimacy, and signalling a call to deference on the basis of the skill and knowledge they are supposed to evidence, is undermined. Replaced with weak proxies such as paramedic fatigues, and/or reduced to secondary importance in favour of establishing rapport with athletes, demonstrating community affinity, or receiving support from non-medical colleagues, means that the tactics typically granting medical staff authority in this field are vulnerable not just to resistance but also co-optation and exploitation by fraudsters. Alongside the general vulnerability of each mechanism medics possess for achieving power, the unchecked possibility of such fraud has alarming implications for the standards of care that athletes in these sports can expect to receive.

\section{Conclusion}

Our study adds further weight of evidence to the well-established observation that, in sport settings, medical staff often lack the power needed to effectively care for the health of athletes. By adopting a theoretical and methodological perspective that centres on the agency of medics, we have extended this discussion by foregrounding the social accomplishment of power as it happens in situ. The conceptual framework we have adopted centralises the 'intersubjective accomplishment' of power. This has enabled us to show that status, authority, influence and the like require ongoing efforts to establish and defend within and through strategic interactions with others, always remaining vulnerable to contestation within environments that do not allow any such position of power to be taken for granted. This perspective may prove useful for other sociological studies of sport wherein 
critical, structuralist, and even some poststructuralist theories tending towards more static or deterministic conceptualisations of power, are not adequately attentive to the role of individual agency in the situated, contested, dynamic social construction of power relations at the microsociological level (Prus, 1999).

With respect to the practical implications of our study, the insights generated here may be of use in helping to prepare medical staff to enter the "unusual clinical environment" of sport (Devitt and McCarthy, 2010:175), particularly those environments where formal regulation providing role clarity is missing. They may also be used to inform training materials for educating athletes, coaches, referees, and promoters about what facilitates or confounds medics' work in such spaces. In this regard, more specific empirical research may be necessary to examine the tactical influence work undertaken by these other players in their engagement with medics (as well as each other). This may help to more comprehensively map out overlapping power relations in the field, as well as nascent, established, or transitory alliances that form at different moments between them - a topic of practical importance, but also one that may be of significant theoretical interest to the sociology of sport.

\section{Notes}

1 We use the term 'show' to denote the typical staging of competitions in all of these sports (except, perhaps, BJJ) as spectator-oriented events.

2 One exception here is the UK-based advisory group, Safe MMA, who offer guidance over medical procedures at MMA shows, as well as pre-fight clearance protocols and a medical suspension system to temporarily exclude injured athletes from participation. However, Safe MMA - as with each of the bodies noted here - does not have the ability to enforce its policies throughout the sport, and the clear majority of MMA events we visited were not Safe MMA-compliant.

3 Although lack of space precludes a detailed discussion of this, we were told by interviewees in our study of some events where medical support was completely missing, albeit that such events were understood to be a rarity. Besides insurers' or venue managers' possible insistence on medical cover, this was otherwise put in place by savvy promoters recognising the liabilities they could incur following athletes' serious injury or death had they not secured medical cover for their events. Still, these all remain informal mechanisms for ensuring some level of medical provision was made.

4 Official data from Sport England (2019) suggest approximately 830,000 adults are regularly involved in combat sports and martial arts. Not all of these participate in the specific disciplines listed here, although anecdotally it would appear that these all remain popular or are growing in popularity, indicated by the prevalence of competitive events held more or less every weekend around the country at the time of writing.

5 Despite the differences in the rules between these sports, it was common for athletes to compete in multiple disciplines, and also for event staff (including referees and medics) to work across them as well. This makes our sample less diverse in form than may first appear.

6 A commissioner is an event staffer who ensures the smooth running of shows, performing duties such as walking competitors to the ring/cage, monitoring corner teams' equipment and conduct, and controlling access to the ring or cage door, etc.

7 Pre-fight screening was the only consistent feature of medics' work across our sample, insomuch as they all did some form of this - with the exception of BJJ events where the numbers of matches (usually in the hundreds) precluded it. As discussed at the outset, there is no formal policy requirement for these checks to take place, yet they remain a common feature of the field regardless, and in our study these were either insisted upon by the medics or asked for by promoters.

8 We only saw this happen three times out of the hundreds of bouts making up our sample. However, one doctor told us "We pull at least one match on pretty much every [top level promotion] show, for one reason or another" (Luke, A\&E consultant).

9 A rules talk typically involves all fighters, their coaches and entourages being briefed by the referee(s) on technical and procedural rules for the event at hand. 


\section{References}

Anderson L and Jackson S (2012) Competing loyalties in sports medicine: Threats to medical professionalism in elite, commercial sport. International Review for the Sociology of Sport 48(2): 238-256.

Athens L (2010) Naturalistic inquiry in theory and practice. Journal of Contemporary Ethnography 39(1): 87-125.

Braun V, Clarke V and Weate P (2016) Using thematic analysis in sport and exercise research. In Smith B and Sparkes AC (Eds.) Routledge Handbook of Qualitative Research in Sport and Exercise. London: Routledge, pp.191-205.

Channon A, Matthews CR and Hillier M (2020) Medical care in unlicensed combat sports: A need for standardised regulatory frameworks. Journal of Science and Medicine in Sport 23(3): 237-240.

Channon A, Matthews CR and Hillier M (in press) 'This must be done right, so we don't lose the income': Medical care and commercial imperatives in mixed martial arts. In: Wagg S and Pollock A (Eds.) The Palgrave Handbook of Sport, Politics and Harm. Basingstoke: Palgrave Macmillan.

Devitt BM and McCarthy C (2010) 'I am in blood stepp'd in so far': Ethical dilemmas and the sports team doctor. British Journal of Sports Medicine 44(3): 175-178.

Dingwall R and Lewis P (Eds.) (1983) The Sociology of the Professions: Lawyers, Doctors and Others. Basingstoke: Macmillan.

Fletcher S, Breitbach AP and Reeves S (2017) Interprofessional collaboration in sports medicine: Findings from a scoping review. Health and Interprofessional Practice 3(2): 1-15.

Freidson E (1960) Client control and medical practice. American Journal of Sociology 65(4): 374-382.

Freidson E (1970) Profession of Medicine: A Study of the Sociology of Applied Knowledge. New York, Dodd: Mead.

Goffman E (1959) The Presentation of Self in Everyday Life. New York, Anchor.

Hanson SS (2018) 'He didn't want to let his team down': The challenge of dual loyalty for team physicians. Journal of the Philosophy of Sport 45(3): 215-227.

Horobin G (1983) Professional mystery: The maintenance of charisma in general medical practice. In Dingwall R and Lewis P (Eds.) The Sociology of the Professions: Lawyers, Doctors and Others. Basingstoke: Macmillan, pp.84-105.

Jensen AR, Maciel RC, Petrigliano FA, Rodriguez JP and Brooks AG (2017) Injuries sustained by the mixed martial arts athlete. Sports Health 9(1): 64-69.

Kotarba JA (2001) Conceptualizing sports medicine as occupational health care: Illustrations from professional rodeo and wrestling. Qualitative Health Research 11(6): 766-779.

Malcolm D (2006) Unprofessional practice? The status and power of sport physicians. Sociology of Sport Journal 23(4): 376-395.

Malcolm D (2016) Confidentiality in sports medicine. Clinics in Sports Medicine 35(2): 205-215.

Malcolm D (2017) Sport, Medicine and Health: The Medicalization of Sport? London, Routledge.

Malcolm D, Scott-Bell A and Waddington I (2017) The provision of medical care in English football: An update. Journal of Science and Medicine in Sport 20(12): 1053-1056.

Moss S (2014) White-collar boxing is too dangerous to be left unlicensed. The Guardian. Online at: https://www.theguardian.com/commentisfree/2014/jun/27/white-collar-boxing-dangerousunlicensed-lance-ferguson-prayogg-death, accessed 20 Feb 2020. 
Pike ECJ (2005) 'Doctors just say "rest and take ibuprofen"': A critical examination of the role of 'nonorthodox' health care in women's sport. International Review for the Sociology of Sport 40(2): 201219.

Pilnick A and Dingwall $R$ (2011) On the remarkable persistence of asymmetry in doctor/patient interaction: A critical review. Social Science \& Medicine 72(8): 1374-1382.

Prus R (1999) Beyond the Power Mystique: Power as Intersubjective Accomplishment. Albany, NY: SUNY Press.

Roderick M, Waddington I and Parker G (2000) Playing hurt: Managing injuries in English professional football. International Review for the Sociology of Sport 35(2): 165-180.

Rice T (2010) 'The hallmark of a doctor': The stethoscope and the making of medical identity. Journal of Material Culture 15(3): 287-301.

Rice S (2016) Joao Carvalho death: Conor McGregor suggests fight could have been stopped earlier. The Independent. Online at: https://www.independent.co.uk/sport/general/mma/joao-carvalhodeath-conor-mcgregor-suggests-fight-could-have-been-stopped-earlier-a6980926.html, accessed 20 Feb 2020

Safai $P$ (2003) Healing the body in the 'culture of risk': Examining the negotiation of treatment between sport medicine clinicians and injured athletes in Canadian intercollegiate sport. Sociology of Sport Journal 20(2): 127-146.

Scott A (2012) Making compromises in sports medicine: An examination of the health-performance nexus in British Olympic sports. In: Malcolm D and Safai P (Eds.) The Social Organisation of Sports Medicine: Critical Socio-Cultural Perspectives. London: Routledge, pp.227-246.

Scott A (2014) Sport and exercise medicine's professional project: The impact of formal qualifications on the organization of British Olympic medical services. International Review for the Sociology of Sport 49(5): 575-591.

Scott A and Malcolm D (2015) 'Involved in every step': How working practices shape the influence of physiotherapists in elite sport. Qualitative Research in Sport, Exercise and Health 7(4): 539-556.

Sport England (2019) Active Lives Survey May 2018/19 Report. Online at: https://www.sportengland.org/know-your-audience/data/active-lives/active-lives-data-tables, accessed 20 Feb 2020

Strong PM and Dingwall R (1997) The Ceremonial Order of the Clinic: Parents, Doctors and Medical Bureaucracies. London: Routledge.

Theberge N (2008) The integration of chiropractors into healthcare teams: A case study from sport medicine. Sociology of Health \& IIIness 30(1): 19-34.

Theberge N (2009) 'We have all the bases covered': Constructions of professional boundaries in sports medicine. International Review for the Sociology of Sport 44(2-3): 265-281.

Tucker A (2004) Ethics and the professional team physician. Clinics in Sports Medicine 23(2): 227-241.

Turner BS (1995) Medical Power and Social Knowledge. London: Sage.

Waddington I (2012) Sports medicine, client control and the limits of professional autonomy. In: Malcolm D and Safai P (Eds.) The Social Organisation of Sports Medicine: Critical Socio-Cultural Perspectives. London: Routledge, pp.204-226.

Waddington I and Roderick M (2002) Management of confidentiality in English professional football clubs: Some ethical problems and issues. British Journal of Sports Medicine 36(2): 118-123.

Waddington, I, Scott-Bell, A and Malcolm D (2019) The social management of medical ethics in sport: Confidentiality in English professional football. International Review for the Sociology of Sport 54(6): 649-665. 
Walk SR (1997) Peers in pain: The experiences of student athletic trainers. Sociology of Sport Journal 14(1): 22-56.

Wright E (2018) Fast-track fisticuffs? An ethnographic exploration of time and white-collar boxing. International Review for the Sociology of Sport Online First, doi:10.1177/1012690218815139. 